\title{
Arterial Oxygen Tension Threshold Range for the Onset of Arousal and Breathing in Fetal Sheep ${ }^{1}$
}

\author{
SHABIH U. HASAN AND ANITA RIGAUX \\ Department of Pediatrics and Reproductive Medicine Research Group, The University of Calgary, \\ Alberta, Canada
}

\begin{abstract}
Mechanisms for the control of episodic fetal breathing movements or the onset of continuous breathing at birth remain unknown. Lung distension with $100 \% \mathrm{O}_{2}$ at a continuous positive airway pressure of $30 \mathrm{~cm} \mathrm{H}_{2} \mathrm{O}$ may induce arousal and continuous breathing. To investigate 1 ) the threshold range of arterial oxygen tension $\left(\mathrm{PaO}_{2}\right)$ for the onset of arousal and breathing and 2) the graded response of breathing to various levels of $\mathrm{PaO}_{2}$, we studied 10 fetal sheep between 135 and $142 \mathrm{~d}$ of gestation (term $=147 \pm 2 \mathrm{~d}$ ). Each fetus was instrumented to record sleep states, diaphragmatic electromyogram, arterial pH, and blood gas tensions. $\mathrm{PaO}_{2}$ threshold was determined through an indwelling $\mathrm{O}_{2}$ sensor catheter. Fetal lungs were distended at a continuous positive airway pressure of $\mathbf{4 0}$ cm $\mathrm{H}_{2} \mathrm{O}$ with $100 \% \quad \mathrm{~N}_{2}$ or with $\mathrm{O}_{2}$ ranging from 40 to $100 \%$ via an in situ endotracheal tube. At the onset of arousal $(n=10), \mathrm{PaO}_{2}$, arterial carbon dioxide tension, and $\mathrm{Hb} \mathrm{O}_{2}$ saturation increased from control values of 21.7 \pm 0.75 torr $(2.9 \pm 0.09 \mathrm{kPa}), 41.8 \pm 1.1$ torr $(5.47 \pm 0.15$ $\mathrm{kPa})$, and $52.9 \pm 2.6 \%$ to $65.6 \pm 9.6$ torr $(8.74 \pm 1.28$ $\mathrm{kPa}), 46.9 \pm 1.3$ torr $(6.25 \pm 0.17 \mathrm{kPa})$, and $92.9 \pm 2.06 \%$, respectively, whereas the $\mathrm{pH}$ decreased from $7.31 \pm 0.006$ to $7.27 \pm 0.009$ (mean $\pm \mathrm{SEM} ; p=\mathbf{0 . 0 0 1}, \mathbf{0 . 0 4}, \mathbf{0 . 0 0 2}$, and 0.001 , respectively). Seven of 10 fetuses breathed continuously. In these fetuses, $\mathrm{PaO}_{2}$ and arterial carbon dioxide tension further increased and $\mathrm{pH}$ decreased; however, no further significant increase in $\mathrm{Hb} \mathrm{O}_{2}$ saturation was observed. Breathing stopped at a $\mathrm{PaO}_{2}$ of $38.5 \pm 9.5$ torr $(5.1 \pm 1.3 \mathrm{kPa})$ but could be restarted by increasing the $\mathrm{PaO}_{2}$. In response to an increase in fetal $\mathrm{PaO}_{2}(30-60$ torr; 4-8 kPa), amplitude of breathing and total respiratory output significantly increased from the control values. Further increases in $\mathrm{PaO}_{2}$ or $\mathrm{Hb} \mathrm{O}_{2}$ saturation did not significantly affect the respiratory output. $\mathrm{Hb} \mathrm{O}_{2}$ saturation and arterial pH had the most confounding effects on frequency and amplitude of breathing, respectively. Among the various sleep states, arousal had the most profound effects on respiratory output. We conclude that 1 ) very high levels of $\mathrm{PaO}_{2}$ are not necessary to initiate arousal and continuous breathing and 2) further increments in $\mathrm{Hb} \mathrm{O}_{2}$ saturation above the threshold level have no significant effect on breathing responses. (Pediatr Res 32: 342-349, 1992)
\end{abstract}

\section{Abbreviations}

AP, amniotic pressure

Received November 27, 1991; accepted May 4, 1992

Correspondence: Dr. Shabih U. Hasan, Department of Pediatrics, Faculty of Medicine, University of Calgary, 3330 Hospital Dr. NW, Calgary, Alberta, T2N $4 \mathrm{~N} 1$, Canada.

Supported by grants from The Christie Unit for the Study of Human Reproduction and by the External Grants Program of the Hospital for Sick Children Foundation, Toronto, Grant XG91-049.

'Presented in part at the Annual Meeting of the Society for Pediatric Research, April 29-May 03, 1991, New Orleans, LA.
BP, blood pressure

CPAP, continuous positive airway pressure

$\mathbf{E M G}_{\mathrm{Di}}$, Diaphragmatic electromyogram

$\mathbf{E M G}_{\mathrm{Nk}}$, nuchal electromyogram

EOG, electro-oculogram/eye movements

FBM, fetal breathing movements

ECoG, electrocorticogram

HV-ECoG, high-voltage ECoG or electrocortical activity LV-ECoG, low-voltage ECoG or electrocortical activity

ID, inner diameter

OD, outer diameter

$\mathrm{PaO}_{2}$, arterial oxygen tension

$\mathrm{PaCO}_{2}$, arterial carbon dioxide tension

Fetuses of mammalian species make episodic breathing movements $(1,2)$. To maintain an independent life, the fetus must establish continuous breathing at birth. Mechanisms for the control of episodic FBM or the establishment of continuous breathing at birth remain unknown. In sheep, during late gestation, FBM occupy $40 \%$ of the total time and normally occur only during LV-ECoG but are absent during HV-ECoG (3). Recent studies have shown that an increase in fetal $\mathrm{PaO}_{2}$ achieved by distending the fetal lungs with $100 \% \mathrm{O}_{2}$ at a CPAP of $30 \mathrm{~cm}$ $\mathrm{H}_{2} \mathrm{O}$ may stimulate FBM during both $\mathrm{LV}$ - and $\mathrm{HV}$-ECoG $(4,5)$. In our previous study (5) initiation of breathing was always associated with the onset of fetal arousal and was critically dependent on fetal maturity. However, in these studies, fetal $\mathrm{PaO}_{2}$ levels were as high as 250 torr $(33.3 \mathrm{kPa})$. Furthermore, the range of $\mathrm{PaO}_{2}$ has also been very wide $(4,5)$, and it is not known whether there is a graded response of FBM to various levels of $\mathrm{PaO}_{2}$. Therefore, we designed a study to investigate 1) the $\mathrm{PaO}_{2}$ threshold range for the onset of arousal and breathing and 2) the graded response of breathing to various levels of $\mathrm{PaO}_{2}$.

\section{MATERIALS AND METHODS}

Animal preparation. Ten time-dated pregnant ewes underwent surgery between 129 and $133 \mathrm{~d}$ of gestation, and the fetuses were studied between 135 and $142 \mathrm{~d}$ of gestation (term $=147 \pm 2 \mathrm{~d}$ ). Surgery was performed under halothane general anesthesia; $4 \%$ for induction and 1.5 to $2 \%$ for maintenance. Instrumentation of the fetus included implantation of 1) four Teflon-coated and color-coded electrode wires (Conner Wire Company, Chatsworth, CA), 2) a carotid arterial catheter, 3) a jugular venous catheter, 4) an endotracheal tube, and 5) two amniotic catheters. The details of surgical procedures have been given elsewhere (5). Briefly, a pair of electrode wires was implanted over the parietal area through two holes drilled in the fetal skull to record ECoG, whereas the EOG was obtained by implanting a silver-coated, oval-shaped electrode in the lateral rectus muscle of one eye. The $\mathrm{EMG}_{\mathrm{Nk}}$ was recorded by suturing a pair of electrodes in the 
lateral neck muscle. $\mathrm{ECoG}, \mathrm{EOG}$, and $\mathrm{EMG}_{\mathrm{Nk}}$ were used to define the fetal sleep states. The $E M G_{D i}$ was recorded from a pair of electrodes implanted in the right hemidiaphragm through an incision in the 10th intercostal space. The fetal carotid artery was catheterized with a $5 \mathrm{Fr}$ neonatal $\mathrm{O}_{2}$ sensor catheter (Neocath, NA 1005, Biomedical Sensors Ltd., High Wycombe, England) to continuously monitor the fetal $\mathrm{PaO}_{2}$, record $\mathrm{BP}$ and heart rate, and withdraw blood samples to analyze $\mathrm{pH}$ and blood gas tensions; a polyvinyl catheter $(2.0 \mathrm{~mm}$ ID, $3.0 \mathrm{~mm}$ OD; Portex, Hythe, Kent, UK) was placed in the jugular vein to administer antibiotics. To apply CPAP to the fetal lungs, a polyvinyl endotracheal tube $(4.8 \mathrm{~mm}$ ID, $7.9 \mathrm{~mm}$ OD; Tygon Norton Plastics, Akron, $\mathrm{OH}$ ) was inserted through an incision $2.0 \mathrm{~cm}$ below the thyroid cartilage, advanced for $5-7 \mathrm{~cm}$, and transfixed ( 0 -silk) to the trachea. Two ( 4.0 silk) sutures were tied around the trachea to minimize the air leak during experiments. To decrease the dead space, the free end of the endotracheal tube was connected to a serrated $Y$ connector (polypropylene, $6.4 \mathrm{~mm}$ OD; Nalgene 6152, Sybron Corp., Rochester, NY). The free ends of the $Y$ connector were, in turn, connected to two polyvinyl extension tubes (4.8 $\mathrm{mm}$ ID, $7.9 \mathrm{~mm}$ OD, Tygon) serving as inspiratory and expiratory extension tubes. Two polyvinyl catheters $(4.9 \mathrm{~mm}$ ID, $7.0 \mathrm{~mm}$ OD and $2.0 \mathrm{~mm}$ ID, $3.0 \mathrm{~mm}$ OD: Tygon) were placed in the amniotic cavity and secured to the back of the fetal neck. The smaller diameter amniotic catheter was used to monitor the AP and also to subtract the fetal BP, whereas the larger amniotic catheter was connected (Perfectum Adapters; Popper \& Sons, Inc., New Hyde Park, NY) to one of the $\mathrm{Y}$-endotracheal tubes to facilitate the tracheoamniotic fluid flow. The second extension of the endotracheal tube remained plugged when no experiments were being conducted. In addition to the fetal instrumentation, a polyvinyl catheter $(2.4 \mathrm{~mm}$ ID; $4.0 \mathrm{~mm}$ ID) was inserted in the maternal jugular vein to infuse fluids intraoperatively and to administer antibiotics postoperatively. After the instrumentation was completed, the fetus was returned to the amniotic cavity and all fetal and maternal incisions were sewn in layers. Routine postoperative management included food and water ad libitum, antibiotic prophylaxis for 4 $\mathrm{d}$, and heparinized saline flush and infusion (Harvard infusion pump, model 901; Harvard Apparatus Co., Inc., South Natick, MA) to maintain the patency of vascular catheters.

Data acquisition and analysis. Immediately after surgery, the ewes were housed in metabolic carts and electrophysiologic signals from $E C O G, E O G, E M G_{N k}$, and $E M G_{D i}$ along with $A P$ and $\mathrm{BP}$ were recorded on an eight-channel chart recorder (Gould 2800S; Gould Inc., Cleveland, OH). ECoG EOG, EMG ${ }_{N k}$, and $E G_{D_{i}}$ were amplified and filtered through NeuroLog System (NL 100 AK, 102G 125/6; Medical Systems Corporation, Greenvale, NY) to record frequency ranges of 0.5 to $40 \mathrm{~Hz}, 5$ to 40 $\mathrm{Hz}, 50 \mathrm{~Hz}$ to $1 \mathrm{kHz}$, and $50 \mathrm{~Hz}$ to $1 \mathrm{kHz}$, respectively. The AP and fetal BP were calibrated twice daily and recorded with Statham P23 ID pressure transducers. During experiments, all signals were digitized using an eight-channel Neuro-corder (Neurodata Instruments Corporation, New York, NY) and recorded on a videocassette recorder (model FVH C4000; Fisher, Toronto, Ontario, Canada). The $\mathrm{O}_{2}$ sensor catheter was connected to the monitor (Neocath neonatal oxygen monitor, NM-1001-0) and calibrated at least once a day and more often if a discrepancy existed between the monitor and the blood gas analyzer (IL 1301; Instrumentation Lab Systems, Lexington, MA). The response time of the Neocath $\mathrm{O}_{2}$ monitor system is $60 \pm 30 \mathrm{~s}(90 \%$ step change). Furthermore, this system measures $\mathrm{O}_{2}$ tensions at the subject's temperature.

Continuous FBM were defined as those that not only remained continuous but also occurred during both LV-ECoG and HVECoG. Electrographic criteria were used to define the fetal behavioral states. Active sleep was defined by the simultaneous presence of LV-ECoG and eye movements and absence of nuchal tone; quiet sleep was defined by the simultaneous presence of HV-ECoG and nuchal tone, and absence of eye movements.
Fetal arousal was defined by the simultaneous presence of LVECoG, nuchal tone, and eye movements $(6,7)$.

The analyses of cardiorespiratory and behavioral responses included 1) delineation of all three behavioral states as described above; 2) measurement of lag period in min, defined as the time elapsed between the change of $\mathrm{O}_{2}$ concentration and the onset of arousal and/or breathing; however, the change in $\mathrm{PaO}_{2}$ does not include the $60 \pm 30$-s response time of the monitoring system; 3) integration of $E M G_{D i}$ and the integrated signal measurement of frequency ( $\mathrm{F}$; the number of diaphragmatic contractions per min of breathing time), amplitude of breathing $\left(\int E M G_{D i}\right)$ in arbitrary units, and respiratory output $\left(\mathrm{F} \times \mathrm{EMG}_{\mathrm{Di}}\right)$ during control and at various $\mathrm{PaO}_{2}$ levels as well as during active sleep, quiet sleep, and awake states; control period refers to the time when no experimental maneuvers were being made; 4) measurement of arterial $\mathrm{pH}$ and blood gas tensions; 5) indirect measurements of $\mathrm{Hb} \mathrm{O}_{2}$ saturation; both blood gas tensions and $\mathrm{Hb} \mathrm{O}_{2}$ saturations were corrected to $39.5^{\circ} \mathrm{C} ; 6$ ) systolic, diastolic, and mean BP; and 7) heart rate (beats/min), calculated from the peaks of the systolic BP. To investigate the graded response of breathing to various levels of $\mathrm{PaO}_{2}, \mathrm{PaO}_{2}$ was divided into 1) control, 2) $30-60$ torr $(4.0-8.0 \mathrm{kPa}), 3) 61-120$ torr $(8.0-16$ $\mathrm{kPa}$ ), and 4) $121-300$ torr (16-40 kPa). The corresponding mean \pm SEM and range of $\mathrm{Hb} \mathrm{O}_{2}$ saturations were 1) $52.9 \pm 2.6 \%$, range $40.4-64.1 \%$; 2) $86.3 \pm 1.94 \%$, range $73.3-94.1 \%$; 3) 97.2 $\pm 0.47 \%$, range $95.1-99.2 \%$; and 4$) 99.7 \pm 0.1 \%$, range $99.1-$ 99.9\%.

Experimental design. No experiments were done for at least 4 $\mathrm{d}$ after surgery and only after fetal breathing, arterial $\mathrm{pH}$, and blood gas tensions were within the physiologic range, which in our laboratory usually occurs within $48 \mathrm{~h}$. The experimental design is shown in Figure 1. Before each experiment, the physiologic variables AP, BP, ECoG, EOG, $\mathrm{EMG}_{\mathrm{Nk}}$, and $\mathrm{EMG}_{\mathrm{Di}}$ were recorded overnight on a chart recorder. For detailed future analyses, all physiologic variables were recorded on a videocassette for at least $3 \mathrm{~h}$ before and during the entire experiment. Experiments were conducted between $1000 \mathrm{~h}$ and $1800 \mathrm{~h}$ to avoid the morning trough and evening peak periods of FBM, respectively. As soon as the control period was obtained, fetal trachea was suctioned through one of the endotracheal tube extensions to remove the existing tracheal fluid, the patency of both endotracheal tubes was checked to avoid pneumothorax, and fetal lungs were distended at a CPAP of $40 \mathrm{~cm} \mathrm{H}_{2} \mathrm{O}$ (relative to atmospheric pressure) using a Baby Bird Ventilator (Bird Corp., Palm Springs, CA) with either $\mathrm{N}_{2}$ or $40 \% \mathrm{O}_{2}$ in randomized order. In our previous study (5), fetal lungs were distended with CPAP of $30 \mathrm{~cm} \mathrm{H}_{2} \mathrm{O}$. However, after completing the protocol in that study, we increased the CPAP to $40 \mathrm{~cm} \mathrm{H}_{2} \mathrm{O}$ and found that an increased number of fetuses could be oxygenated. Therefore, based on those (unpublished) observations, we elected to choose $40 \mathrm{~cm} \mathrm{H} \mathrm{H}_{2} \mathrm{O}$ instead of $30 \mathrm{~cm} \mathrm{H}_{2} \mathrm{O}$. Nitrogen was added to the protocol as a control for gaseous distension. Forty percent $\mathrm{O}_{2}$ concentration was chosen because in our previous studies, $21 \% \mathrm{O}_{2}$ had no significant effect on either breathing or behavior $(4,5)$. Thereafter, $\mathrm{O}_{2}$ concentration was increased in increments of $20 \%$ until an increase in $\mathrm{PaO}_{2}$ and/or effects on breathing or behavior were observed. Various concentrations of $\mathrm{O}_{2}$ were not randomized because, in the past, with a high initial $\mathrm{O}_{2}$ concentration the fetal $\mathrm{PaO}_{2}$ rose rapidly, making the determination of $\mathrm{PaO}_{2}$ threshold impossible. Each concentration of $\mathrm{O}_{2}$ was maintained for at least $2 \mathrm{~h}$. All changes in gas concentration were made only during HV-ECoG. However, once the breathing was established in both LV-ECoG and HV-ECoG, $\mathrm{O}_{2}$ concentration was decreased gradually until the breathing ceased. As soon as the cessation of breathing in quiet sleep was observed, $\mathrm{O}_{2}$ concentration was again increased until a change in breathing and/ or behavior was observed.

Statistical analysis. The onset of breathing and arousal and the graded response of breathing to various levels of $\mathrm{PaO}_{2}$ and $\mathrm{Hb} \mathrm{O} \mathrm{O}_{2}$ saturations were analyzed using analysis of variance for 


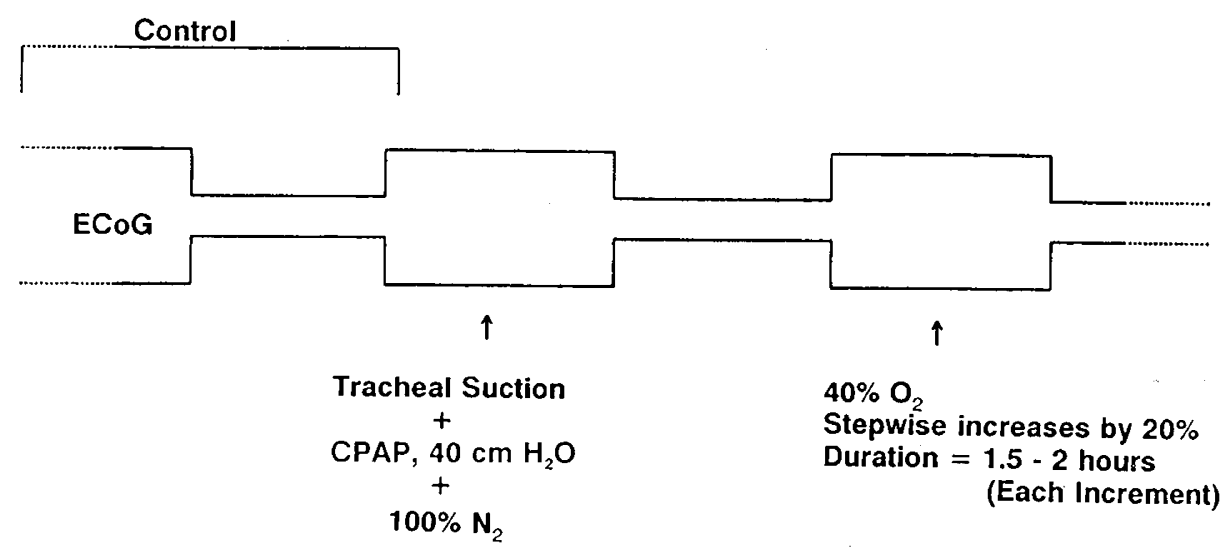

Fig. 1. Experimental design. First, a control period was recorded. Each control period consisted of at least two episodes of LV-ECoG and HVECoG that normally coincided with periods of breathing and apnea, respectively. Then tracheal suction was followed by lung distension at $40 \mathrm{~cm}$ $\mathrm{H}_{2} \mathrm{O}$ with $100 \%$ nitrogen. Thereafter, the inspired gas mixture was changed to $40 \% \mathrm{O}_{2}$ and increased by $20 \%$ until an increase in fetal $\mathrm{PaO}_{2}$ was noted and/or a change in breathing or behavior was observed. Each concentration of inspired gas was humidified, heated to $39.5^{\circ} \mathrm{C}$, and maintained for 1.5 to $2 \mathrm{~h}$.

repeated measures. The significance of differences was assessed by Tukey's procedure (8). The breathing responses were further analyzed while keeping the $\mathrm{pH}, \mathrm{PaCO}_{2}, \mathrm{PaO}_{2}$, and $\mathrm{Hb} \mathrm{O}$ saturations as a continuous variable. For this purpose, analysis of covariance was carried out with three dependent variables (respiratory output, frequency, and amplitude of breathing), adjustments were made for animal differences, and tests were considered for the impact of $\mathrm{pH}, \mathrm{PaCO}_{2}, \mathrm{PaO}_{2}$, and $\mathrm{Hb} \mathrm{O}_{2}$ saturations. Regression diagnostic techniques were used to assess the adequacy of the fit, and logarithmic transformations were considered for each variable, but the findings remained comparable to the untransformed analysis. Because $\mathrm{Hb} \mathrm{O}_{2}$ saturation is a dependent variable, analysis of covariance was also performed without the $\mathrm{Hb} \mathrm{O}_{2}$ saturation as a covariant. Correlation coefficient analysis was used to determine the association between $\mathrm{pH}$ and $\mathrm{PaO}_{2}$. The changes in $\mathrm{pH}, \mathrm{PaCO}_{2}$, and $\mathrm{PaO}_{2}$ at the onset of arousal were compared with the control values by paired $t$ test. An unpaired $t$ test was used to determine whether the arterial $\mathrm{pH}$ and blood gas tensions were different in the fetuses that breathed continuously than in those that did not breathe continuously. $n$ denotes the number of fetuses. All data are presented as mean \pm SEM, and a $p$ less than 0.05 was considered significant.

These studies were approved by the Animal Care Committee of the University of Calgary.

\section{RESULTS}

Threshold range of $\mathrm{PaO}_{2}$ for arousal and breathing. Results from the 10 fetuses manifesting arousal given in Figure 2 show that at the onset of arousal $\mathrm{PaO}_{2}$ increased from the control value of $21.7 \pm 0.75$ torr $(2.89 \pm 0.1 \mathrm{kPa})$ to $65.6 \pm 9.6$ torr $(8.78 \pm$ $1.28 \mathrm{kPa}, p=0.001)$, whereas the $\mathrm{pH}$ decreased from $7.31 \pm$ 0.006 to $7.27 \pm 0.009(p=0.002) . \mathrm{PaCO}_{2}$ increased from $41.8 \pm$ 1.1 torr $(5.47 \pm 0.15 \mathrm{kPa})$ to $46.9 \pm 1.3$ torr $(6.25 \pm 0.17 \mathrm{kPa}, p$ $=0.041)$. $\mathrm{Hb} \mathrm{O}_{2}$ saturation also increased from the control value of $52.9 \pm 2.6 \%$ to $92.9 \pm 2.06 \%$ at the onset of arousal (analysis of variance; Tukey's procedure confidence interval -37.407 to $-51.143)$.

Seven of 10 fetuses breathed continuously during both LV$\mathrm{ECoG}$ and HV-ECoG. Arterial $\mathrm{pH}$ and blood gas tensions from these fetuses are summarized in Figure 3. In these fetuses, $\mathrm{PaO}_{2}$ increased from a control value of $22.1 \pm 0.82$ torr $(2.95 \pm 0.11$ $\mathrm{kPa})$ to $69.4 \pm 12.7$ torr $(9.3 \pm 1.7 \mathrm{kPa}, p=0.008)$ and $114.8 \pm$ 18.2 torr $(15.3 \pm 2.43 \mathrm{kPa}, p=0.002)$, whereas $\mathrm{pH}$ decreased from $7.30 \pm 0.007$ to $7.27 \pm 0.01(p=0.04)$ and $7.24 \pm 0.01(p$ $=0.004$ ) at the onset of arousal and breathing and during breathing in quiet sleep respectively (Fig. 3). The decrease in $\mathrm{pH}$ and the increase in $\mathrm{PaO}_{2}$ during breathing in $\mathrm{HV}-\mathrm{ECOG}$ were also significant when compared with the arousal values $(p=0.02$ for both changes). $\mathrm{PaCO}_{2}$ also significantly increased from control value of $43.2 \pm 1.3$ torr $(5.76 \pm 0.17 \mathrm{kPa})$ to $47.9 \pm 1.4$ torr $(6.39 \pm 0.18 \mathrm{kPa})$ during breathing in quiet sleep, whereas it remained unchanged $(46.5 \pm 1.9$ torr; $6.20 \pm 0.25 \mathrm{kPa})$ at the onset of arousal and breathing ( $p=0.044$ and 0.30 , respectively; Fig. 3). In these fetuses, $\mathrm{Hb} \mathrm{O}$ saturation increased from a control value of $54.1 \pm 2.4 \%$ to $94.53 \pm 4.1 \%$ and $96.54 \pm 2.6 \%$ at the onset of arousal and stimulation of breathing during quiet sleep, respectively (confidence interval -40.704 to -52.810 and -40.338 to -52.955 , respectively). There was no significant difference in $\mathrm{Hb} \mathrm{O}_{2}$ saturation during arousal and breathing in
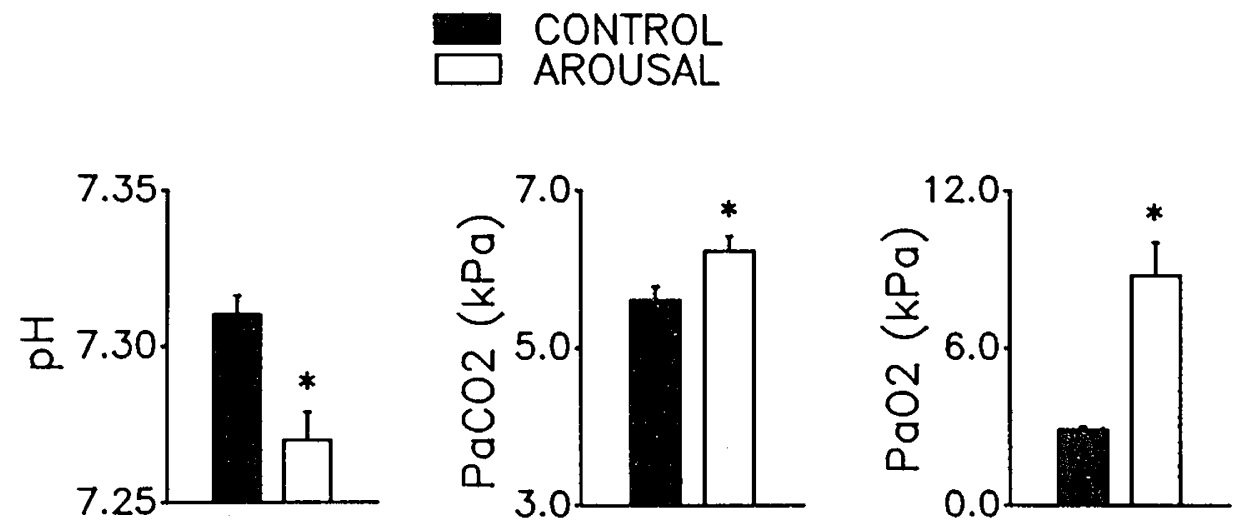

Fig. 2. Arterial $\mathrm{pH}$ and blood gas tensions during control and at the onset of arousal in all 10 fetuses. pH decreased and both $\mathrm{PaCO}_{2}$ and $\mathrm{PaO}_{2}$ increased (mean \pm SEM; $p=0.002,0.041$, and 0.001 , respectively). 

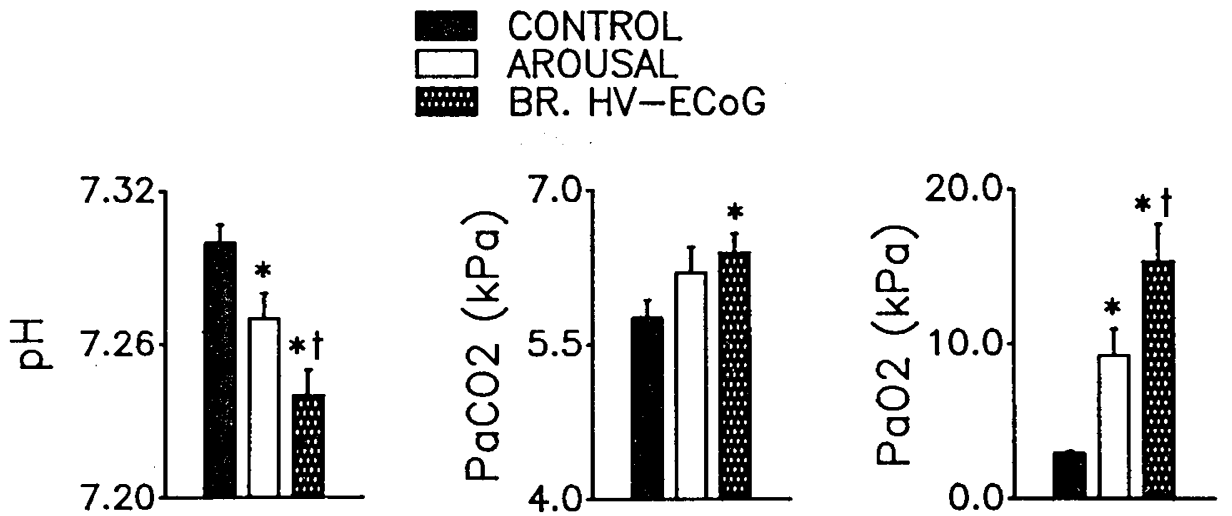

Fig. 3. Arterial $\mathrm{pH}$ and blood gas tensions in seven fetuses that breathed continuously during both LV-ECoG and HV-ECoG. pH significantly decreased from control values during arousal $(p=0.04)$. Further decrease in $\mathrm{pH}$ was observed during breathing in HV-ECoG $(p=0.004)$. The decrease in $\mathrm{pH}$ during breathing in HV-ECoG was also significantly different when compared with the arousal values $(p=0.02)$. PaCO changed $^{2}$ significantly from the control values only during breathing in $\mathrm{HV}-\mathrm{ECoG}$ (analysis of variance; $p=0.044$ ). $\mathrm{PaO}_{2}$ significantly increased from the control values during arousal and breathing in $\mathrm{HV}-\mathrm{ECoG}\left(p=0.008\right.$ and 0.002 , respectively). The increase in $\mathrm{PaO}_{2}$ from arousal values during breathing in HV-ECoG was also significant $(p=0.02) .^{*}, p<0.05$ from the control values; $\dagger, p<0.05$ from the arousal values.

quiet sleep (confidence interval -6.297 to +6.519 ). Breathing stopped and $\mathrm{HV}-\mathrm{ECOG}$ prevailed when the $\mathrm{PaO}_{2}$ was decreased to $38.5 \pm 9.5$ torr $(5.13 \pm 1.3 \mathrm{kPa})$; however, breathing could be restarted by increasing the $\mathrm{PaO}_{2}$. There were no statistically significant differences in $\mathrm{pH}, \mathrm{PaCO}_{2}, \mathrm{PaO}_{2}$, or gestational ages $(p$ $=0.369,0.635,0.09$, and 0.208 , respectively) of the fetuses that breathed continuously when compared with the fetuses that did not breathe continuously. Figures 4 and 5 are representative tracings from the fetuses that showed arousal and continuous breathing.

The inspired $\mathrm{O}_{2}$ concentration was $100 \%$ for the three fetuses that manifested arousal but did not breathe continuously, whereas the minimum inspired $\mathrm{O}_{2}$ concentration varied widely among the seven fetuses that manifested both arousal and continuous breathing. Five fetuses manifested arousal and the onset of breathing during administration of $100 \% \mathrm{O}_{2}$, whereas the inspired $\mathrm{O}_{2}$ concentrations were 40 and $60 \% \mathrm{O}_{2}$ in the remaining two fetuses. Although no lag was observed between the monitored increase in $\mathrm{PaO}_{2}$ and the stimulation of breathing, a delay of up to $2 \mathrm{~min}$ is possible because of the $60 \pm 30$-s (90\% step change) response time of the indwelling $\mathrm{O}_{2}$ sensor catheter and monitor system.

Graded response of breathing to various levels of $\mathrm{PaO}_{2}$ and $\mathrm{Hb}$ $\mathrm{O}_{2}$ saturation. Amplitude and frequency of breathing and total respiratory output under control and various levels of $\mathrm{PaO}_{2}$ are summarized in Figure 6. In response to an increase in fetal $\mathrm{PaO}_{2}$ (30-60 torr; 4-8 $\mathrm{kPa}$ ), both amplitude of breathing and respiratory output increased significantly from control values. The $\mathrm{Hb}$ $\mathrm{O}_{2}$ saturation increased from control values of $52.9 \pm 2.6 \%$ (range $40.4-64.1 \%$ ) to $86.3 \pm 1.9 \%$ (range $73.3-94.1 \%$, confidence interval -3.76 to -18.125 ). Further significant increases in $\mathrm{PaO}_{2}$ or $\mathrm{Hb} \mathrm{O}_{2}$ saturation did not result in a further increase in these variables (Fig. 6). Frequency of breathing did not significantly increase until the range of $\mathrm{PaO}_{2}$ was between 60 and 120 torr $(8.1-16 \mathrm{kPa})$ and the $\mathrm{Hb} \mathrm{O}_{2}$ saturation were $97.2 \pm 0.47 \%$ (range 96.4-99.2\%). Further increase in $\mathrm{PaO}_{2}$ had no significant effect on the frequency of breathing. Similar to the amplitude of breathing and respiratory output, the increase in frequency was not significantly different among the higher levels of $\mathrm{PaO}_{2}$ or $\mathrm{Hb}$ $\mathrm{O}_{2}$ saturations (Fig. 6).

Interactions of $\mathrm{pH}, \mathrm{PaCO}_{2}, \mathrm{PaO}_{2}$, and $\mathrm{Hb} \mathrm{O}_{2}$ saturation on breathing responses. When $\mathrm{pH}, \mathrm{PaCO}_{2}, \mathrm{PaO}_{2}$, and $\mathrm{Hb} \mathrm{O}_{2}$ saturation were included as covariants, $\mathrm{Hb} \mathrm{O}_{2}$ saturation had the most profound effect on the frequency of breathing $(p=0.024)$, whereas the decrease in $\mathrm{pH}$ had the most significant effect on the amplitude of breathing $(p=0.05)$. Effects of $\mathrm{pH}$ on breathing amplitude remained the most significant covariant even when $\mathrm{Hb} \mathrm{O}_{2}$ saturation was excluded from the analysis $(p=0.021)$.
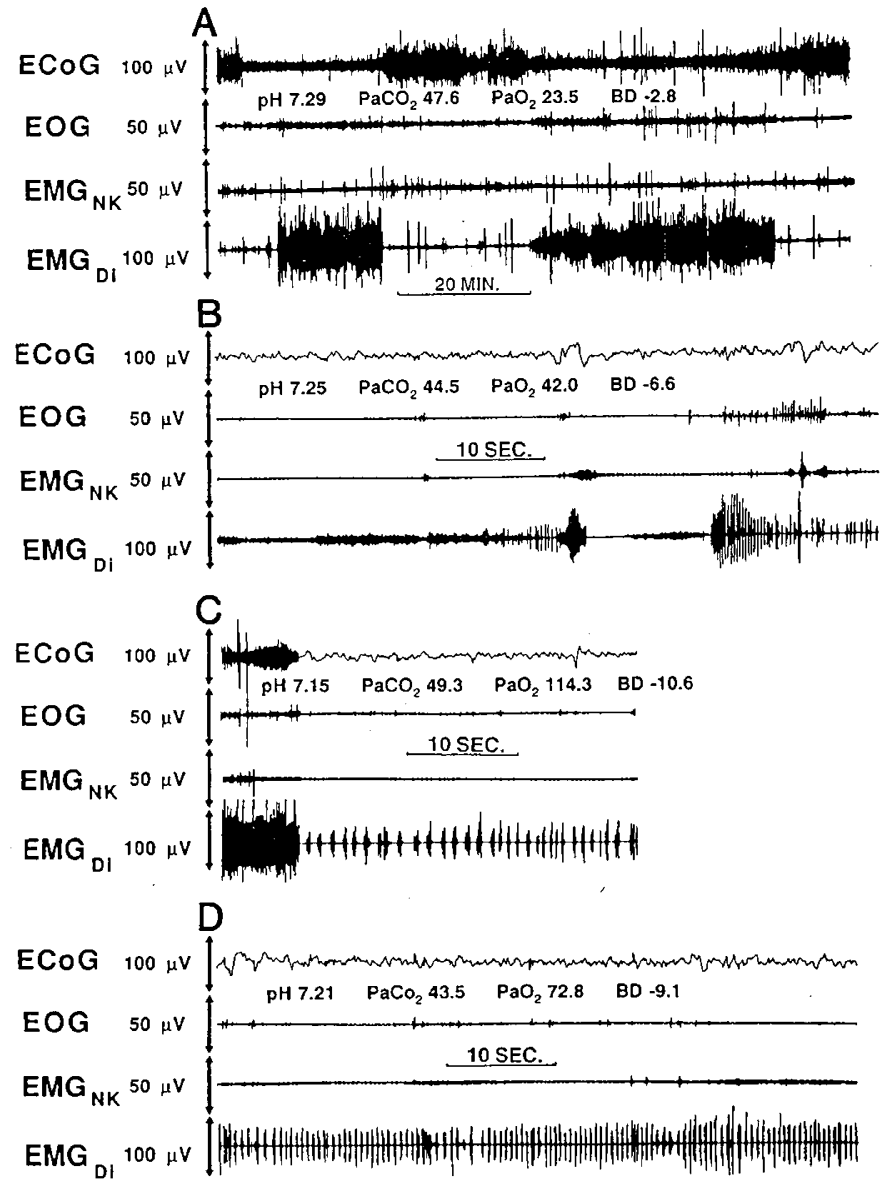

Fig. 4. Representative tracing under control and experimental conditions from a fetus at $140 \mathrm{~d}$ of gestation. $A$, Control recording showing the presence of FBM only during LV-ECoG and the absence of FBM during HV-ECoG. $B$, Onset of arousal and initiation of breathing, arousal being defined as the simultaneous presence of LV-ECoG, eye movements, and nuchal tone. $C$, Continuation of breathing during both LVECoG and HV-ECoG. $D$, Continuation of breathing at a $\mathrm{PaO}_{2}$ of 72.8 torr $(9.7 \mathrm{kPa})$.

However, when the $\mathrm{Hb} \mathrm{O}_{2}$ saturation was excluded as a covariant, the change in $\mathrm{PaCO}_{2}$ had the most profound effect on the frequency of breathing $(p=0.015)$. Excluding the effects of $\mathrm{pH}$, $\mathrm{PaO}_{2}$, and $\mathrm{Hb} \mathrm{O}_{2}$ saturation, the rate of change in frequency of breathing was 3.0 per min per unit of $\mathrm{PaCO}_{2}$ ( 1 torr or 0.1333 

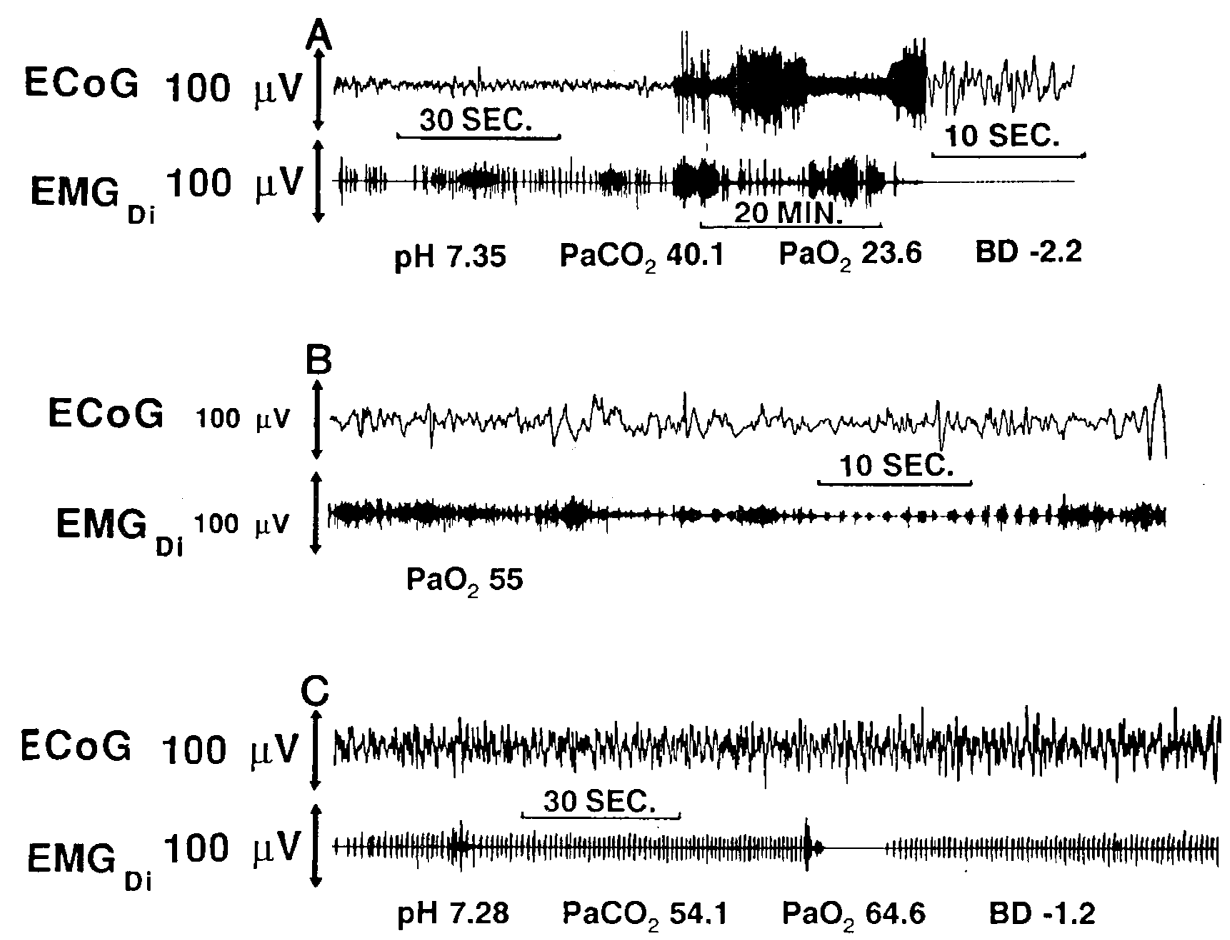

Fig. 5. Representative tracing from a fetus at a gestational age of $137 \mathrm{~d}$ showing control, onset, and stimulation of breathing during $\mathrm{HV}$-ECoG. During control $(A)$, an irregular pattern of breathing is present during LV-ECoG and is absent during HV-ECoG. At the onset of breathing, the $\mathrm{PaO}_{2}$ as recorded from the indwelling $\mathrm{O}_{2}$ sensor catheter increased from the control value of 23.6 torr $(3.15 \mathrm{kPa})$ to 55 torr $(7.33 \mathrm{kPa})$. Breathing continued during $\mathrm{HV}-\mathrm{ECoG}$ at a $\mathrm{PaO}_{2}$ of 64.6 torr $(8.61 \mathrm{kPa})$. During this period, a decrease in $\mathrm{pH}$ and an increase in $\mathrm{PaCO}_{2}$ also was observed.
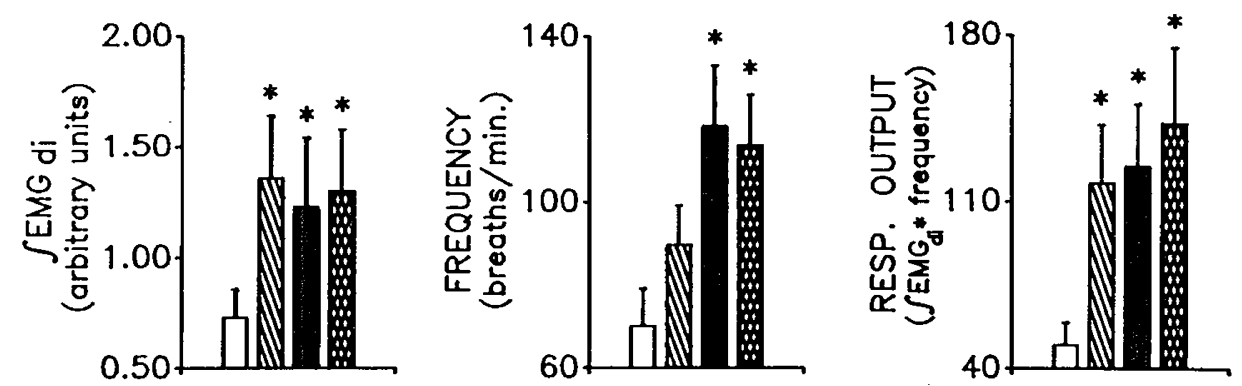

Fig. 6. Figure showing the $\int E M G_{\mathrm{Di}}$ (breathing amplitude in arbitrary units), frequency (breaths/min), and respiratory output $\left(\int E M G_{D i} \times\right.$ frequency) during control and three different ranges of $\mathrm{PaO}_{2}$. Breathing amplitude and respiratory output significantly increased from control values during various $\mathrm{PaO}_{2}$ levels; however, no graded response was noted among the higher $\mathrm{PaO}_{2}$ levels. Frequency of breathing significantly increased at $\mathrm{PaO}_{2}$ levels of greater than 61 torr $(8.1 \mathrm{kPa})$ but again no graded response was observed.

$\mathrm{kPa}$ ), whereas independent of $\mathrm{PaCO}_{2}$ and $\mathrm{PaO}_{2}$, the amplitude of breathing changed by 0.68 arbitrary units per 0.1 unit change in $\mathrm{pH}$. The effects of $\mathrm{pH}$ and $\mathrm{PaCO}_{2}$ on respiratory output were also significant ( $p=0.009$ and 0.006 , respectively).

Effects of sleep states on breathing. The effects of various sleep states on breathing responses are summarized in Figure 7. Amplitude of breathing increased significantly only during arousal $(p=0.02)$, remaining unaffected during both active and quiet sleep states ( $p=0.62$ and 0.22 , respectively). In contrast, frequency of breathing increased during all sleep states $(p=0.03-$ 0.02 ); when compared with the control values, however, this increase was not significantly different among various sleep states $(p=0.52-0.92)$. Respiratory output increased during arousal and quiet sleep ( $p=0.003$ and 0.01 , respectively) but did not reach the statistical significance during rapid eye movement sleep $(p=0.12$; Fig. 7).

Cardiovascular responses. No significant effects on systolic, diastolic, and mean BP or heart rate were noted during lung distension and oxygenation in any sleep state (Table 1).

\section{DISCUSSION}

Our present data provide new evidence that high fetal $\mathrm{PaO}_{2}$ is not required to induce continuous FBM. In fact, the threshold range of $\mathrm{PaO}_{2}$ falls well within the physiologic range described by other investigators both in sheep and human newborns at or shortly after birth $(9,10)$. Furthermore, we have shown that an increase in $\mathrm{Hb} \mathrm{O}_{2}$ saturation above the threshold range does not significantly affect the total fetal respiratory output.

Baier et al. (4) originally made the observation that a high fetal $\mathrm{PaO}_{2}$ achieved by distending fetal lungs with $100 \% \mathrm{O}_{2}$ may initiate continuous fetal breathing. We subsequently showed that such stimulation of breathing was critically dependent on fetal maturity and was always associated with the onset of arousal (5). An increase in fetal $\mathrm{PaO}_{2}$ has been achieved by many investigators (11-15). However, FBM were not observed in any of these studies because of either fetal immaturity or methodologic reasons (1117). The mechanisms through which an increase in fetal $\mathrm{PaO}_{2}$ 


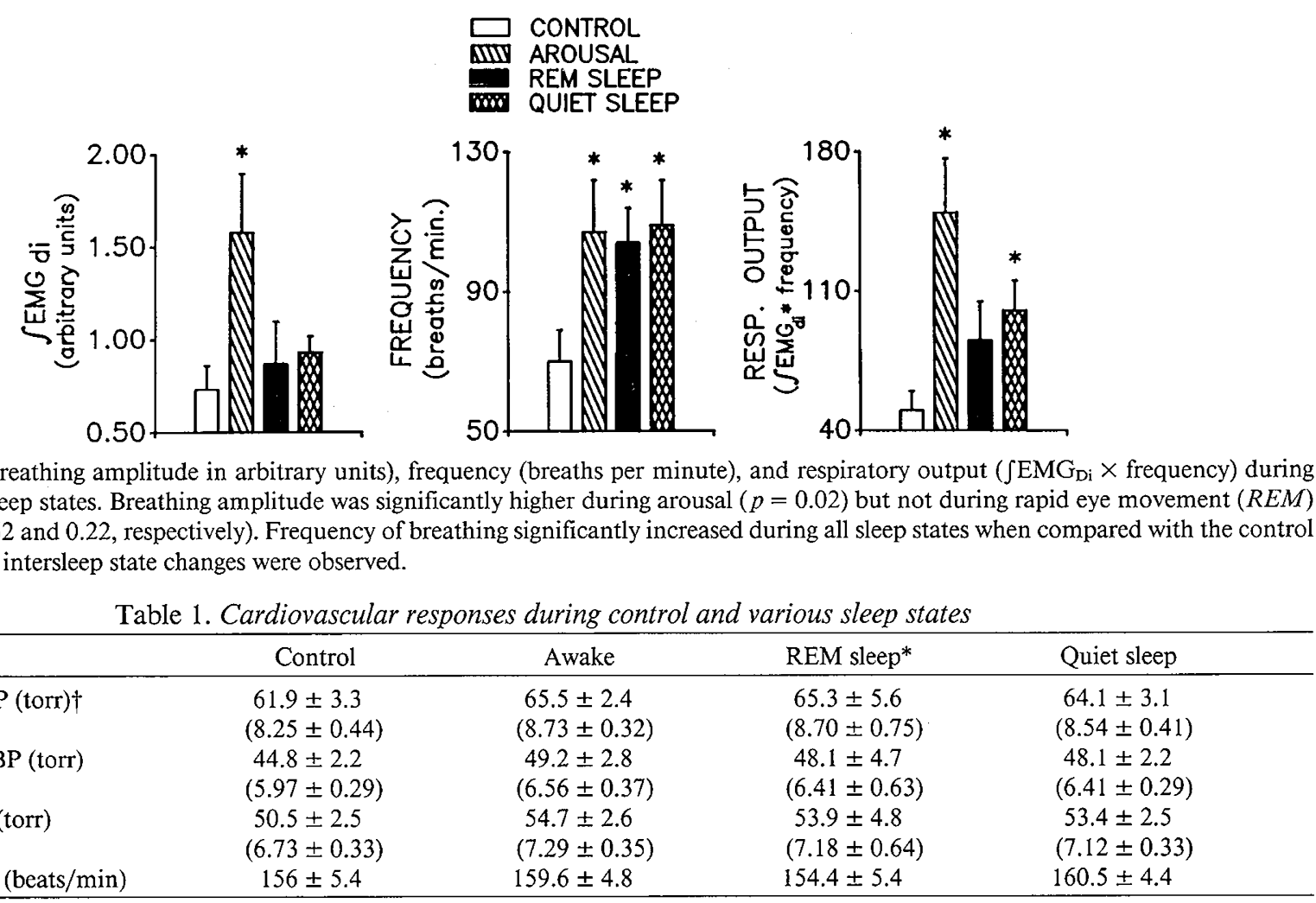

Fig. 7. $\int E M G_{D i}$ (breathing amplitude in arbitrary units), frequency (breaths per minute), and respiratory output $\left(\int E M G_{D i} \times\right.$ frequency) during control and various sleep states. Breathing amplitude was significantly higher during arousal $(p=0.02)$ but not during rapid eye movement ( $R E M)$ or quiet sleep ( $p=0.62$ and 0.22 , respectively). Frequency of breathing significantly increased during all sleep states when compared with the control values. No significant intersleep state changes were observed.

Table 1. Cardiovascular responses during control and various sleep states

\begin{tabular}{lcccc}
\hline & Control & Awake & REM sleep* & Quiet sleep \\
\hline Systolic BP (torr) $\dagger$ & $61.9 \pm 3.3$ & $65.5 \pm 2.4$ & $65.3 \pm 5.6$ & $64.1 \pm 3.1$ \\
$(\mathrm{kPa})$ & $(8.25 \pm 0.44)$ & $(8.73 \pm 0.32)$ & $(8.70 \pm 0.75)$ & $(8.54 \pm 0.41)$ \\
Diastolic BP (torr) & $44.8 \pm 2.2$ & $49.2 \pm 2.8$ & $48.1 \pm 4.7$ & $48.1 \pm 2.2$ \\
$(\mathrm{kPa})$ & $(5.97 \pm 0.29)$ & $(6.56 \pm 0.37)$ & $(6.41 \pm 0.63)$ & $(6.41 \pm 0.29)$ \\
$\mathrm{Mean}$ BP (torr) & $50.5 \pm 2.5$ & $54.7 \pm 2.6$ & $53.9 \pm 4.8$ & $53.4 \pm 2.5$ \\
$(\mathrm{kPa})$ & $(6.73 \pm 0.33)$ & $(7.29 \pm 0.35)$ & $(7.18 \pm 0.64)$ & $(7.12 \pm 0.33)$ \\
Heart rate (beats/min) & $156 \pm 5.4$ & $159.6 \pm 4.8$ & $154.4 \pm 5.4$ & $160.5 \pm 4.4$ \\
\hline
\end{tabular}

* REM, rapid eye movement.

$\dagger 1$ torr $=0.1333 \mathrm{kPa}$.

cause stimulation of breathing remain unknown, but several possibilities exist.

In our current study, fetal $\mathrm{PaCO}_{2}$ increased and $\mathrm{pH}$ decreased; both these changes were statistically significant and are well known to stimulate fetal breathing $(1,2,18,19)$. Inasmuch as the increase in $\mathrm{PaO}_{2}$ and $\mathrm{PaCO}_{2}$, the decrease in $\mathrm{pH}$, onset of arousal, and stimulation of breathing occur simultaneously, it is difficult to establish a cause and effect relationship. Neither can one differentiate between dependent and independent variables. The reasons for such an increase in $\mathrm{PaCO}_{2}$ remain unclear. It is conceivable that with an increase in $\mathrm{PaO}_{2}$ umbilical blood flow decreased, leading to a decrease in the unloading of $\mathrm{CO}_{2}$, whereas further increase in $\mathrm{PaCO}_{2}$ during $\mathrm{HV}$-ECoG breathing resulted from increased work of breathing. Also, at that time, further increase in $\mathrm{PaO}_{2}$ occurred and at least some of the increases in fetal $\mathrm{PaCO}_{2}$ might have been due to the Haldane effect. We believe that stimulation of breathing, at least during LV-ECoG, might have occurred because of an increase in $\mathrm{PaCO}_{2}$. However, it is well established that $\mathrm{CO}_{2}$-stimulated fetal breathing is always restricted to rapid eye movement sleep $(1,2,18,19)$, whereas the stimulation of breathing in our current study occurred during both sleep states. Furthermore, several studies showed that, when fetal sleep states were measured, an increase in fetal $\mathrm{PaCO}_{2}$ levels as high as 100 torr $(13.33 \mathrm{kPa})$ did not lead to either arousal or breathing during HV-ECoG $(18,19)$. At the onset of arousal in all 10 fetuses, although there was a statistically significant increase in $\mathrm{PaCO}_{2}$, we are not aware of any study where an increase of 45 torr in $\mathrm{PaCO}_{2}$ was associated with stimulation of FBM $(1,2$, 19-21). However, all hypercapnic studies were done under fetal normoxemic or hypoxemic states, and it is possible that an increase in fetal $\mathrm{PaO}_{2}$ above the normal fetal level alters the central and/or peripheral sensitivity to $\mathrm{CO}_{2}$ tension because hypercapnia does not stimulate fetal breathing under hypoxemic conditions $(1,2)$. Another important and confounding variable in our studies has been the decrease in arterial $\mathrm{pH}$; metabolic acidemia is also well known to stimulate fetal breathing $(22,23)$. Although there appears to be direct correlation between increased
$\mathrm{PaO}_{2}$ and decreased $\mathrm{pH}$, the mechanism(s) for this decrease in $\mathrm{pH}$ also remain(s) unclear. The implications and possible causes of metabolic acidemia have been discussed in detail in our previous communication (5). In summary, although the increase in $\mathrm{PaCO}_{2}$ and/or a decrease in $\mathrm{pH}$ had significant effects on breathing, they are unlikely to be the sole reason for the stimulation of breathing. This notion is supported in our previous study, where stimulation of breathing was observed while $\mathrm{PaCO}_{2}$ and $\mathrm{pH}$ were kept at constant or near-constant values by highfrequency oscillation (4). However, the important issue of increased intrathoracic pressure and its effects on venous return, organ blood flow, and impairment of cardiac output need to be addressed in future studies.

In our current study, we have endeavored to quantify the relative contributions of $\mathrm{pH}$ and $\mathrm{PaCO}_{2}$ to the amplitude and frequency of breathing and respiratory output. Previous studies by Molteni et al. (22) showed that after a minimum lag of $2.5 \mathrm{~h}$ a decrease in $\mathrm{pH}$ caused an increase in both the depth and the frequency of breathing, whereas Hohimer and Bissonnette (23) reported an increase in the incidence of breathing although they did not provide data regarding the frequency or amplitude of breathing. An increase in fetal $\mathrm{PaCO}_{2}$ by maternal rebreathing techniques showed an increase in both frequency and amplitude of breathing. However, an increase in $\mathrm{PaCO}_{2}$, unless compensated, would also cause a decrease in $\mathrm{pH}$. Because $\mathrm{Hb} \mathrm{O}_{2}$ saturation is a dependent variable, analysis of covariance was done with and without it being a covariant. The significant effects of $\mathrm{Hb} \mathrm{O}_{2}$ saturation on breathing frequency might have been caused by $\mathrm{Hb} \mathrm{O}_{2}$ saturation per se being dependent on other confounding variables present in our current study. Excluding $\mathrm{Hb} \mathrm{O}_{2}$ saturation as a covariant, analysis of covariance in our current study suggests that the amplitude and frequency of fetal breathing are affected preferentially but not exclusively by fetal arterial $\mathrm{pH}$ and $\mathrm{PaCO}_{2}$, respectively. Furthermore, this analysis also quantifies the per unit change in breathing responses, which has not been reported previously.

At least three studies recently have suggested a role for respi- 
ratory inhibitory factor(s) released from the placenta $(4,24,25)$. In the study by Adamson et al. (24) umbilical cord occlusion led to gasping movements followed by continuous breathing; subsequent cord release resulted in cessation of breathing. However, during cord occlusion, both $\mathrm{PaCO}_{2}$ and $\mathrm{PaO}_{2}$ increased significantly to very high levels. In two recent studies, Adamson et al. (25) and Baier et al. (4) occluded the umbilical cord while maintaining the $\mathrm{PaCO}_{2}$ near control levels by high-frequency oscillation. However, in the former study (25), baseline $\mathrm{PaO}_{2}$ was considered to be after the initiation of high frequency oscillation at which time $\mathrm{PaO}_{2}$, analyzed at $37^{\circ} \mathrm{C}$, ranged from 38 to 47 torr, whereas in the latter study (4) umbilical cord occlusion induced breathing but in association with a further increase in fetal $\mathrm{PaO}_{2}$. Therefore, further studies are needed to quantitate the relative roles of oxygenation and umbilical cord occlusion. It is controversial although possible that an increase in fetal $\mathrm{PaO}_{2}$ in our studies might have led to a reduction (26-28) or cessation of umbilical-placental blood flow (functional cord occlusion), thereby eliminating the presumed blood-borne respiratory inhibitory factor(s) of placental origin. Iwamoto et al. (14) showed that the net umbilical blood flow did not decrease in response to fetal oxygenation; however, the relative amount of cardiac output to the placenta decreased. Such a relative decrease could have resulted from a significant increase in the left to right shunt at the ductus arteriosus level, inasmuch as an increase in $\mathrm{PaO}_{2}$ might lead to a dramatic decrease in pulmonary vascular resistance and an increase in pulmonary blood flow (29). Also, lungs have been shown to be a major site for the metabolism of prostaglandins (30). Therefore, in response to an increase in fetal $\mathrm{PaO}_{2}$, increased metabolism of prostanoids might have played a more important role in the stimulation of breathing than did the decrease in umbilical blood flow.

In our current study, the amplitude of breathing and total respiratory output did not show a graded effect to various (higher) levels of $\mathrm{PaO}_{2}$. We did not make direct measurements of $\mathrm{Hb} \mathrm{O}_{2}$ saturation; however, indirect measurements of $\mathrm{Hb} \mathrm{O}_{2}$ saturations showed that no further significant increase in $\mathrm{Hb} \mathrm{O}_{2}$ saturation was observed above the threshold level for arousal and breathing. Therefore, it is conceivable that, once the $\mathrm{Hb} \mathrm{O}_{2}$ saturation reached a critical level, further increase in the $\mathrm{Hb} \mathrm{O}_{2}$ saturation regardless of the $\mathrm{PaO}_{2}$ level had no significant effects on various breathing responses. It was also interesting to note that the frequency of breathing remained unchanged during various sleep states, whereas the amplitude of breathing increased only during the awake state. Such an increase might have been due to wakefulness-related cortical influences that have been shown to play a significant role in maintaining the respiratory drive during the awake state (31). Similarly, the significant increase in respiratory output during the awake state was not surprising; however, the increase in respiratory output during quiet sleep rather than active sleep was unexpected because previous studies in newborn human infants have shown the opposite effects $(32,33)$. Such a discrepant increase in respiratory output might have been due to the presence of sensory (mechanoreceptor) input resulting from lung distension, inasmuch as such an input is more important during quiet sleep in the very young infant than in the older child or adult (32).

We previously have shown that the initiation of breathing in response to lung distension and oxygenation always coincided with the onset of arousal and it was not clear whether there was a causal relationship between arousal and breathing (5). In our present study, arousal occurred in three fetuses but breathing did not become continuous, suggesting that breathing and arousal could be uncoupled and factors other than arousal may play an important role in the maintenance of breathing. However, in the remaining seven fetuses, arousal did coincide with the onset of continuous breathing, which is consistent with our previous observations (5). Similar behavioral changes have been reported in both human and sheep newborns at birth $(9,10)$. However, in the study by Baier et al. (4), arousal was observed only during cord occlusion. These discrepancies in fetal behavioral state might have been because of the different criteria used to define fetal arousal as well as different techniques to induce continuous breathing. Most investigators have used the electrographic criteria to define the fetal sleep states $(6,7)$, whereas Rigatto $(34)$ observed the fetus through a Plexiglas window implanted in the ewe's left flank. However, no studies comparing the electrographic and visual observation have been reported in a chronically prepared fetal sheep. This issue is important because arousal not only has been reported in association with the onset of continuous breathing but also has been regarded as a potent respiratory stimulant (35-37). Mechanisms through which lung distension and oxygenation cause arousal remain unknown. In our previous and current studies, absence of arousal during lung distension with nitrogen suggests that lung distension per se does not lead to arousal. This is consistent with the observations made by Sullivan et al. (37) that lung inflation failed to arouse dogs from either quiet or active sleep. Our preliminary data suggest that the arousal response may be at least partially mediated via vagal afferents and not afferents from the peripheral chemoreceptors $(38,39)$.

In summary, this study has demonstrated that the maintenance of fetal breathing and the onset of arousal in response to lung distension and oxygenation does not require very high levels of $\mathrm{PaO}_{2}$ and that there is no graded response of breathing above a critical level of $\mathrm{Hb} \mathrm{O}_{2}$ saturation. Further studies are warranted to investigate the precise mechanisms through which increased fetal $\mathrm{PaO}_{2}$ initiate these behavioral and breathing responses and to help us better understand the factors for the onset of continuous extrauterine breathing. Such studies may also have clinical implications inasmuch as disturbances in the control of breathing and behavior are associated with significant neonatal mortality and morbidity $(40,41)$.

Acknowledgments. The authors thank Drs. Tak Fung and Gordon Fick for their assistance in the statistical analysis and Michelle Cavanaugh for her excellent secretarial assistance in the preparation of the manuscript.

\section{REFERENCES}

1. Bryan AC, Bowes G, Maloney JE 1986 Control of breathing in the fetus and the newborn. In: Fishman AP (ed) Handbook of Physiology, The Respiratory System II. American Physiological Society, Bethesda, MD, pp 621-647

2. Jansen AH, Chernick V 1991 Fetal breathing and development of control of breathing. J Appl Physiol 70:1431-1446

3. Dawes GS, Fox HE, Leduc BM, Liggins GC, Richards RT 1972 Respiratory movements and rapid eye movement sleep in the fetal lamb. J Physiol (Lond) 220:119-143

4. Baier RJ, Hasan SU, Cates D, Hooper DA, Nowaczyk B, Rigatto H 1990 Effect of various concentrations of oxygen and umbilical cord occlusion on fetal breathing and behavior in sheep. J Appl Physiol 68:1597-1604

5. Hasan SU, Rigaux A 1991 The effects of lung distension, oxygenation, and gestational age on fetal behavior and breathing movements in sheep. Pediatr Res 30:193-201

6. Szeto HH, DJ Hinman 1985 Prenatal development of sleep-wake patterns in sheep. Sleep 8:347-355

7. Ioffe S, Jansen AH, Russell BH, Chernick V 1980 Sleep, wakefulness and the monosynaptic reflex in fetal and newborn lambs. Pflugers Arch 388: $149-157$

8. Armitage P, Berry G (eds) 1988 Statistical Methods in Medicine, 2nd Ed. Blackwell Scientific Publications, Oxford, UK, pp 296-357

9. Oliver Jr TK, Demis JA, Bates GD 1961 Serial blood gas tensions and acidbase balance during the first hour of life in human subjects. Acta Paediatr Scand 50:346-360

10. Desmond MM, Franklin RR, Vallbona C, Hill RM, Plumb R, Arnold H, Watts J 1963 The clinical behavior of the newly born. J Pediatr 62: 307-325

11. Assali NS, Kirschbaum TH, Dilts PV 1968 Effects of hyperbaric oxygen on uteroplacental and fetal circulation. Circ Res 22:573-588

12. Morin FD, Egan EA, Ferguson W, Lundgren CEG 1988 Development of pulmonary vascular response to oxygen. Am J Physiol 254:H542-H546

13. Willis DM, Anderson DF, Thornburg KL, Faber JJ 1985 Alteration of arterial gas composition by positive pressure ventilation in the unanesthetized fetal lamb in utero. Biol Neonate 47:295-304

14. Iwamoto HS, Teitel D, Rudolph A 1987 Effects of birth-related events on blood flow distribution. Pediatr Res 22:634-640 
15. Teitel DF, Iwamoto HS, Rudolph AM 1990 Changes in the pulmonary circulation during birth-related events. Pediatr Res 27:372-378

16. Blanco CE, Martin CB, Rankin J, Landauer M, Phernetton T 1988 Changes in fetal organ flow during intrauterine mechanical ventilation with or without oxygen. J Dev Physiol 10:53-62

17. Blanco CE, Chen V, Maertzdorf W, Bamford OS, Hanson M 1990 Effect of hyperoxia $\left(\mathrm{PaO}_{2} 50-90 \mathrm{mmHg}\right)$ on fetal breathing movements in the unanaesthetized fetal sheep. J Dev Physiol 14:235-241

18. Jansen AH, Ioffe S, Russell BJ, Chernick V 1982 Influence of sleep state on the response to hypercapnia in fetal lambs. Respir Physiol 48:125-142

19. Rigatto H, Lee D, Davi M, Moore M, Rigatto E, Cates D 1988 Effect of increased arterial $\mathrm{CO}_{2}$ on fetal breathing and behavior in sheep. $\mathrm{J}$ Appl Physiol 64:982-987

20. Moss IR, Scarpelli EM 1979 Generation and regulation of breathing in utero: fetal $\mathrm{CO}_{2}$ response test. J Appl Physiol 47:527-531

21. Koos BJ, Sameshima H, Power GG 1987 Fetal breathing, sleep states and cardiovascular responses to graded hypoxia in sheep. J Appl Physiol 62: 1033-1039

22. Molteni RA, Melmed MH, Sheldon RE, Jones MD, Meschia G 1980 Induction of fetal breathing by metabolic acidemia and its effect on blood flow to the respiratory muscles. Am J Obstet Gynecol 136:609-620

23. Hohimer AR, Bissonnette JM 1981 Effect of metabolic acidosis on fetal breathing movements in utero. Respir Physiol 43:99-106

24. Adamson SL, Richardson BS, Homan J 1987 Initiation of pulmonary gas exchange by fetal sheep in utero. J Appl Physiol 62:989-998

25. Adamson SL, Kuipers IM, Olson DM 1991 Umbilical cord occlusion stimulates breathing independent of blood gases and pH. J Appl Physiol 70: 1796-1809

26. Nyberg R, Westin B 1957 The influence of oxygen tension and some drugs on human placental vessels. Acta Physiol Scand 39:216-227

27. Lewis BV 1968 The response of isolated sheep and human umbilical arteries to oxygen and drugs. J Obstet Gynaecol Br Commonw 75:87-91

28. Campbell AGM, Dawes GS, Fishman AP, Hyman AI, James GB 1966 The oxygen consumption of the placenta and foetal membranes in the sheep. $\mathbf{J}$ Physiol (Lond) 182:439-464

29. Teitel DF, Iwamoto HS, Rudolph AM 1987 Effects of birth-related events on central blood flow patterns. Pediatr Res 22:557-566

30. Piper $P$, Vane $J 1971$ The release of prostaglandins from lung and other tissues. Ann NY Acad Sci 180:363-383

31. Fink BR 1961 Influence of cerebral activity in wakefulness on regulation of breathing. J Appl Physiol 16:15-20

32. Finer NN, Abrams IF, Taeusch HW 1976 Ventilation and sleep states in newborn infants. J Pediatr 89:100

33. Thach BT, Frantz ID, Adler SM, Taeusch HW, Avery ME 1975 Vagal influence on inspiratory duration in premature infants as a function of postnatal and gestational age. Fed Proc 34:358(abstr)

34. Rigatto $\mathrm{H} 1984 \mathrm{~A}$ new window on the chronic fetal sheep model. In: Nathanielsz PW (ed) Animal Models in Fetal Medicine III. Perinatology Press, Ithaca NY, pp 57-67

35. Phillipson EA, Bowes G 1986 Control of breathing during sleep. In: Fishman AP (ed) Handbook of Physiology. Section 3: The Respiratory System. Vol 2: Control of Breathing, part 2. American Physiological Society, Bethesda, MD, pp 649-683

36. Thoppil CK, Belan MA, Cowen CP, Mathew OP 1991 Behavioral arousal in newborn infants and its association with termination of apnea. J Appl Physiol $70: 2479-2484$

37. Sullivan CE, Kozar LF, Murphy E, Phillipson EA 1979 Arousal, ventilatory, and airway responses to bronchopulmonary stimulation in sleeping dogs. Appl Physiol 47:17

38. Hasan SU, Rigaux A 1992 Effect of bilateral vagotomy on oxygenation, arousal and breathing movements in fetal sheep. $J$ Appl Physiol (in press)

39. Hasan SU, Salkauskas A, Jansen A 1990 The effect of bilateral carotid sinus nerve denervation on continuous fetal breathing movements (FBM) induced by oxygenation and lung distension in sheep. Pediatr Res 27:356A(abstr)

40. Martin RJ, Miller MJ, Carlo WA 1986 Pathogenesis of apnea in preterm infants. J Pediatr 109:733-741

41. Steinschneider A 1972 Prolonged apnea and the sudden infant death syndrome: clinical and laboratory observations. Pediatrics 50:646-654 